\title{
ASÍ QUE PASEN CINCO AÑOS: FEDERICO GARCÍA LORCA Y EL PROBLEMA DE LO TRÁGICO
}

\author{
WHEN FIVE YEARS PASS: FEDERICO GARCÍA LORCA \\ AND THE PROBLEM OF THE TRAGIC
}

\section{Claudio CASTRO FILHO}

Universidade de Coimbra (Portugal)

\begin{abstract}
Resumen: Aunque la relectura de la tragedia ática por parte de Federico García Lorca se halla plasmada en su archiconocida trilogía rural, sus obras de acento vanguardista guardan un agudo cuestionamiento sobre el sentido filosófico de lo trágico en el imaginario reciente. Así que pasen cinco años, drama de 1931 que forma parte de su ciclo de "comedias irrepresentables", expresa, así, una compleja investigación filosófica sobre el sujeto trágico. Por un lado, la obra se vale de un ambiente onírico de corte surrealista y de una deconstrucción de las categorías subjetivas muy al gusto expresionista, revelando el fuerte diálogo del autor granadino con las vanguardias centroeuropeas. Por el otro, en las entrelíneas de la forma se halla una reflexión filosófica conectada con universos aparentemente dispares, como lo son el auto sacramental de los Siglos de Oro y las reflexiones sobre lo trágico de Nietzsche y Unamuno. Este capítulo se propone desglosar dicha problemática en la obra de Lorca, buscando comprender algunas de las coincidencias y discrepancias entre el modelo trágico antiguo y los nuevos planteamientos sobre la tragedia advenidos de una dramaturgia de vanguardia.
\end{abstract}

Palabras clave: Federico García Lorca, Así que pasen cinco años, comedias irrepresentables, herencia barroca, tragedia, trágico.

Abstract: Although Federico García Lorca's re-reading of the greek tragedy is embodied in his famous rural trilogy, his avant-garde works have an acute questioning of the philosophical sense of the tragic in the recent imaginary. When five years pass (1931), part of its cycle of "unrepresentable comedies", expresses a complex philosophical research on the subject tragic. On the one hand, the work is worth a dream environment of surreal court and a deconstruction of subjective categories very to the expressionist taste, revealing the strong dialogue of the author with the European avant-garde . On the other, beside of the form there is a philosophical reflection connected with seemingly disparate universes, as are the auto sacramental of the Siglo de Oro and the reflections on the tragic of Nietzsche 
62 Tropelías. Revista de Teoría de la Literatura y Literatura Comparada, 33 (2020)

Claudio Castro Filho

and Unamuno. This chapter proposes to break down this problem in Lorca's work, seeking to understand some of the coincidences and discrepancies between the old tragic model and the new approaches to the tragedy of an avant-garde dramaturgy.

Key Words: Federico García Lorca, When five years pass, unrepresentable comedies, Baroque inheritance, tragedy, tragic. 

unque el regreso de Lorca a la forma de la tragedia griega va a consumarse en sus conocidas tragedias rurales (Bodas de sangre, Yerma, La casa de Bernarda Alba), Así que pasen cinco años constituye una profunda investigación filosófica sobre lo trágico. La lectura de los grandes autores de la tragedia ática es una asignatura en la que Lorca aprueba con un sobresaliente por lo menos desde finales de los veinte, conllevando la construcción de una aguda percepción de la dialéctica trágica, a la que hay que sumar los modernos tratados filosóficos sobre el tema: la literatura de Nietzsche y Unamuno, sobre todo. La particularidad de la mirada trágica en Así que pasen quizás radique en este enfrentamiento entre el paganismo nihilista de Nietzsche y la intuición religiosa de Unamuno: sistemas filosóficos aparentemente opuestos, pero que coinciden en las grandes preguntas heredadas de los griegos sobre la condición existencial.

De ahí que la perplejidad ante la muerte y el imperio del destino se compaginen con el asombro gongorino y las formas alegóricas o "nódulos técnicos" (Rodríguez, 1994, p. 63) de los autos sacramentales de los Siglos de Oro. A fin de cuentas, la escritura lorquiana acoge concepciones de inspiración que respectan a matrices místicas y románticas de la noción de instinto (cf. Alonso Valero, 2005, p. 10) y que hacen coincidir el asombro que veía Lorca en Góngora con la Trieb o pulsión nietzscheana. La fenomenología de la temporalidad que pone en marcha Así que pasen cinco años (de ahí el subtítulo Leyenda del Tiempo) apunta hacia una filosofía del tiempo tan griega como calderoniana.

Así que pasen cinco años cuenta con una acción dramática más o menos sencilla: la obra habla de un Joven que espera el regreso de su Novia, que se ha marchado en un viaje transatlántico de cinco años antes de consumar la boda. La espera desembocará en total frustración: a las vísperas del reencuentro entre los prometidos, la Novia se ve arrebatada por una furiosa pasión por un Jugador de Rugby. Todo el drama se desarrolla desde ahí y mediante un marco de inacción, conllevando un recorrido dramático donde el protagonista absoluto, uno de los más inquietantes personajes masculinos del teatro de Lorca, parece desdoblar su frustración amorosa y su dolor vital en un caleidoscopio de figuras que, poco a poco, van cristalizando su muerte en vida. A raíz de la inacción, de la espera con la que se procrastinó la boda y del miedo a la soledad, al futuro sin descendencia y a la muerte, Así que pasen cinco años constituye, ante todo, un ensayo teatral sobre el paso del tiempo.

Desde la sinopsis ya se reconoce el corte metateatral de la obra, puesto que los personajes no están nombrados, sino que responden meramente por su función en el drama. Poco a poco, el juego escénico se vuelve todavía más abstracto, en tanto que se difuminan coordinadas geográficas o color local que permitan situarnos con precisión en el tiempo o espacio. La obra se desarrollará en un lugar indecidible entre la realidad y el sueño (tal cual en la celda de Segismundo en el drama de Calderón) y echará mano de herramientas épicas y líricas. Se trata de un drama épico, ya que subvierte las coordinadas cronológicas de la acción aristotélica y apuesta por una narrativa fragmentada y episódica; 
pero se trata también de un drama lírico, porque deconstruye la integridad subjetiva del personaje dramático para convertirlo o multiplicarlo en máscaras y espejismos de fuerte acento metafórico. De ahí que, del Viejo, interlocutor más inmediato del Joven protagonista, nos diga Alonso Valero (2008, p. 46) que "el texto evita decir cuál es el disfraz y cuál es la figura real, o si los dos son reales o ambos son disfraces". Ya sea por la fragmentación del yo que forma parte del espíritu moderno o del inconsciente histórico que menciona Rodríguez (1994, p. 9) respecto a las coordinadas simbólicas y alegóricas de lo trágico en Lorca, el hecho es que la idea del Joven como personaje único, desplegado en un sinnúmero de figuras que funcionan como proyecciones sicológicas suyas, es reiterada por la crítica y se alinea a tendencias dramatúrgicas renovadoras arrancadas por lo menos desde el teatro simbolista (cf. Candeias, 2012).

Pero hay que convenir en que esa problemática trágica, aquí, no es una cuestión de género literario, sino que abarca otras capas filosóficas. Recordemos que Así que pasen se inserta en el proyecto lorquiano de las llamadas comedias irrepresentables (junto con El público y Comedia sin título), porque a lo mejor sí que se trata de una comedia, con su carga irónica y su sentido del humor. Por otro lado, desde la farsa se levanta un edificio trágico que sin duda cimienta otras problematizaciones lorquianas de la relación entrañable entre el tiempo y la tragedia. Está en juego la idea del héroe ante la fatalidad, perdido en un laberinto o callejón sin salida. La procrastinación amorosa es el error trágico, que conlleva una abnegación vital o muerte en vida, que remueve al héroe lorquiano y, así pues, el Joven anticipa el sino de Doña Rosita y Yerma en las obras homónimas.

Lo parecido de Así que pasen con Doña Rosita es enorme, ya que en el caso del drama granadino de 1935 la protagonista obedece al mismísimo problema: el posponer la boda, a raíz de un viaje transatlántico, que al fin y al cabo se revelará una espera de por vida. En ambas obras, la comedia y el drama, el reloj marcará siempre las seis de la tarde, configurando un estancamiento temporal en el instante eterno de lo que no pudo ser. Doña Rosita tendrá, en efectivo, a Penélope como modelo, de ahí que los elementos materiales que concretan su espera desmesurada digan respecto al costurar su propio ajuar. La idea de las telas y tejidos intactos como señal de la fatalidad del desuso — ahí está, de la muerte en vida - está asimismo perfectamente plasmada en el diálogo entre el Joven y el Maniquí en el acto segundo de Así que pasen. A semejanza de la costumbre hasta hoy día de muchos pueblos ibéricos, donde se guarda el traje de la boda para después reutilizárselo como mortaja, el Maniquí llora por la sinrazón que es ostentar el vestido de unas bodas rotas:

JOVEN.

¿Qué cantas, dime?

MANIQUí.

muerte que no tuve nunca, dolor de velo sin uso, con llanto de seda y pluma. Ropa interior que se queda helada de nieve oscura, sin que los encajes puedan competir con las espumas. 
Telas que cubren la carne serán para el agua turbia. $\mathrm{Y}$ en vez de rumor caliente, quebrado torso de lluvia. ¿Quién usará la ropa buena de la novia chiquita y morena?

(García Lorca, OC, II, pp. 363-364).

La "muerte que no tuve nunca", llorada por un cuerpo-ciborg que se pone en un lugar de indecisión entre lo humano y lo inhumano, sugiere además una equivalencia entre la boda y la muerte, anticipando otro despliegue del proyecto trágico lorquiano: Bodas de sangre. Pero si el protagonista de Así que pasen, tal cual Doña Rosita, se resigna al fado de la soledad, la Novia de Bodas, por su parte y al igual que la Novia de Así que pasen acomete al deseo auténtico y huye con el amante objeto de su arrebatamiento. Pero Lorca tiene claro lo del callejón sin salida que es la tragedia, porque también el que concuerda con el deseo auténtico tiene que enfrentarse a fuerzas contra las que no puede: la fatalidad recae sobre las valientes Novias al igual que sobre Yerma (la que se conformará con un matrimonio infértil y dejará que se vaya su pasión de juventud para ahogarse en su propia frustración, convirtiéndose en asesina). Otra alma inquieta y maculada por la pasión, la Adela de La casa de Bernarda Alba, optará por el autosacrificio, una especie de negación absoluta con la que se resiste al imperio autoritario de la madre devoradora que es Bernarda. Importa, aquí, percibir que, al fin y al cabo, todo el ciclo trágico de Lorca, desde las tragedias imposibles hasta las posibles, ronda una misma cuestión, que parece obedecer a un mismo enredo, aunque con distintos enlaces.

El tema de la descendencia atraviesa todo el ciclo trágico lorquiano, pero asume rasgos particulares en Así que pasen. Hay, por un lado, el arcabuco filosófico de Unamuno, desde donde la descendencia es una especie de fuerza de resistencia ante lo inevitable que es la muerte, un antídoto contra la finitud con el que uno se perpetúa más allá de su jornada vital. Por otro, a semejanza de don Perlimplín, el Joven de Así que pasen es un macho invertebrado: la frustración ante la imposibilidad de descendencia es ante todo una emasculación de la existencia. Perlimplín había preguntado a su criada si hay otra mujer (en el mundo) además de Belisa (García Lorca, OC, II, p. 249). La misma pregunta la lleva adentro el joven de Así que pasen. No hay otra mujer aparte de su Novia y su fatídica infertilidad consuma los innúmeros entredichos sobre su homosexualidad. A fin de cuentas, lo imposible, en Lorca, tiene que ver con lo interdicto, con el "más allá de lo decible" (Rodríguez, 1994, p. 15). "La frustración homosexual de Lorca" es "sin duda una motivación obvia en su proyecto poético" (Rodríguez, 1994, p. 39). La deconstrucción del personaje dramático llevada a cabo por el dramaturgo reitera, así pues, una de sus facetas más claras: la difuminación de la frontera entre el personaje y la voz poética.

Pero la angustia ante la falta de descendencia, el problema de la infertilidad en cuanto frustración sexual es también miedo a la muerte, la muerte como "realidad absoluta, como instante de la fusión entre esencia y existencia, como único desvelamiento posible" (Rodríguez, 1994, p. 54). La certeza de la finitud, que al ser una verdad inexorable asume rasgos trágicos, conlleva la elección de la temporalidad como motivo central. Motivo que puede ponerse de relieve mediante los ya mencionados 
tintes vanguardistas: de ahí la atmósfera de cabaré que se traduce en las diversas máscaras, caretas y disfraces que atraviesan la acción; de ahí la conocida canción del Arlequín en el acto final:

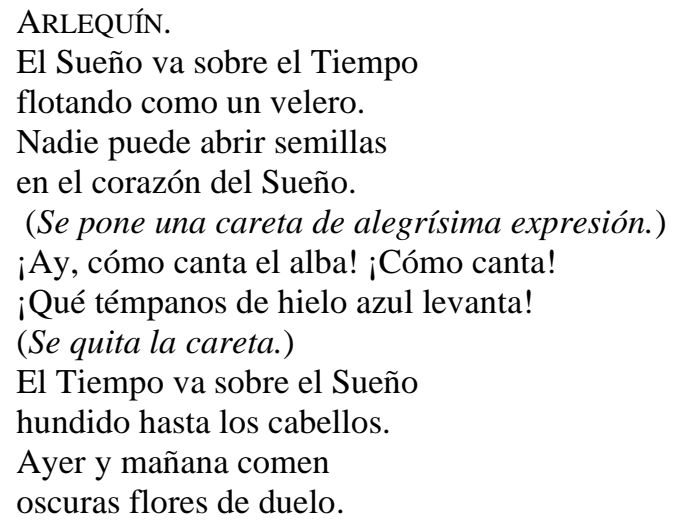

La fuerte subjetivación de la temporalidad, que se convierte en imágenes alegóricas, revelará nuevas huellas nietzscheanas en la concepción lorquiana de lo trágico: ante lo cierto que es la muerte, hay que vivir el aquí y el ahora. Pero el tratamiento alegórico, con el que el Tiempo se vuelve una entidad indescifrable, nos remite de inmediato a un insoslayable referente de Así que pasen cinco años: el auto sacramental. A fin de cuentas, también Calderón hereda de los antiguos la concepción mítica del tiempo como una especie de presente absoluto, lo cual determinará el destino humano, según señala Onians (1988). De ahí que en el auto calderoniano leamos:

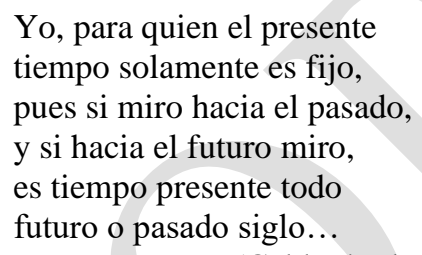

(Calderón de La Barca, La vida es sueño, vv. 332-337).

No es cualquiera quien pronuncia dicha sentencia en el auto calderoniano, sino la Sabiduría en persona. Pero el Joven de Así que pasen afirma el presente absoluto calderoniano por una vía negativa, es decir, por una especie de encarcelación en el instante eterno de lo no vivido. De ahí que se vea él enteramente solapado por el paso del tiempo, el irreductible tiempo cronológico que ejerce el rol de un daimon trágico, una potencia superior al yo contra la que de nada sirve luchar. Pese a que esta percepción temporal esté anclada en la alegoría barroca, el tiempo late a lo largo de Así que pasen cinco años como un torbellino síquico y afectivo que, en cierto modo, recupera el laberinto subjetivo de los románticos, a la vez que dialoga con una obra crucial para pensarse el tiempo de los modernos, como En busca del tiempo perdido, de Proust.

Lo metafórico del tiempo se hace patente, además, en su relación con el espacio, que se halla en Así que pasen desplazado a lugares no reconocibles en la inmediatez de lo real. Estamos, por doquier, en un espacio onírico, más allá de lo consciente; una espacialidad que concuerda con la dimensión de la alegoría barroca y que edifica, por lo tanto, un escenario difuso, donde la ensoñación se instaura a 
través de una atmósfera lunar constantemente aludida en las acotaciones por luces azuladas, de rasgos surrealistas o expresionistas. Esa constante atmósfera onírica concuerda además con el juego metapoético tan presente en la tradición siglodeorista de los autos. Las acotaciones del diálogo entre el Niño y la Gata indican que los personajes "avanzan hacia el público" (García Lorca, OC, II: 340). En el acto final, el escenario de gabinete del acto primero se duplica en un espejismo miniaturizado (García Lorca, $O C$, II: 381), tal cual una iluminación medieval o retablo barroco. El teatro confirma su potencia ficticia a la vez que denuncia ciertos códigos de ficción que atraviesan la propia vida. Esa difuminación de las fronteras espaciales entre escenario y platea (el derrumbe de la cuarta pared) tiene que decir respecto a la atmósfera difusa del sueño, donde lo consciente y lo inconsciente se mezclan y confunden. Se trata, en los términos de Bachelard (1997, pp. 34-35), de una poética de la ensoñación, que abandona el espacio habitual del significado y desplaza la palabra hacia el terreno arquetípico del mito.

Este lugar onírico es asimismo un lugar apto para la tragedia, en aquello que respecta al sentido profético o premonitorio que tenía el sueño para los dramaturgos de la Atenas clásica (cf. Devereux, 1975; Marques, 2006). En definitiva, el tiempo se concreta, en la pieza lorquiana, mediante claves mitológicas, de ahí la figura omnipresente y algo divina del Viejo, una especie de personificación de Cronos (cf. Ucelay, 2006, p. 66; Saillard y Ramond, 1998, pp. 47-56), como interlocutor primero del Joven. Y una vez que se trata de una lectura mitológica de la temporalidad, la obra naturalmente abarca capas filosóficas todavía más amplias que el tiempo cronológico. Y es así como otras categorías clásicas del tiempo formarán parte del juego escénico que nos propone el autor.

Podemos considerar, por una parte, que lo trágico está irremediablemente ligado a aión, el tiempo eterno e inmutable de la verdad platónica, del que cronos es una mera representación (cf. Degani, 2001; Keizer, 1999; Campillo, 1991, pp. 42-43). Y está claro que Así que pasen cinco años se estructura, desde la metateatralidad barroca hasta una problematización del yo muy a la manera de Pirandello, sobre el juego entre verdades y apariencias. Por otra, interesa sobradamente a Lorca la categoría temporal de kairós, el llamado tiempo oportuno, que corresponde a una suspensión inesperada e irrepetible de lo cronológico (Campillo, 1991, pp. 59-60) y que, en la obra que nos ocupa, se pone de manifiesto con doble cara: es el instante máximo de la vitalidad amorosa para la Novia y, por el otro lado, es la inmovilidad de las eternas seis de la tarde para el Joven, su muerte en vida.

La doble cara, el espejismo barroco que separa simétricamente el retablo del público, tal cual nos enseña Foucault (2005, pp. 13-25) a respecto de Las meninas, cimienta por lo tanto la dialéctica trágica sobre la que se mueve el tiempo de Así que pasen. Si, por un lado, el tiempo enseña su faceta inexorable a través de la figura del Viejo — el que dice que "hay que recordar hacia mañana" (García Lorca, $O C$, II, p. 333)—, por el otro, se corresponde con esta misma inexorabilidad la desolación del Niño ante la muerte, muerte que en Lorca es siempre prematura:

Vámonos; de casa en casa

llegaremos donde pacen

los caballitos del agua.

No es el cielo. Es tierra dura 
con muchos grillos que cantan, con hierbas que se menan, con nubes que se levantan, con hondas que lanzan piedras y el viento como una espada. ¡Yo quiero ser un niño, un niño!

(García Lorca, OC, II, p. 344).

La inconformidad del Niño muerto, el que quiere ser lo que ya no es, es ante todo perplejidad y reitera trágicamente el escándalo que es la muerte en la gramática lorquiana. Otra vez resuena en nuestro autor una perspectiva clásica de lo trágico marcada por la soledad y la desolación absoluta del individuo ante la catástrofe: o bien no hay Dios o, si es que hay, se trata de una divinidad sorda. Opera, aquí, el enunciado nietzscheano de la muerte de Dios y, al tiempo, el escepticismo religioso de Unamuno, el que así tradujo la Medea de Séneca (2008, p. 86): "Vete por los hondos espacios del alto firmamento a atestiguar por donde pases que no hay dioses". Si no hay dioses, tampoco hay cielo, de ahí el miedo que azota al Niño muerto:

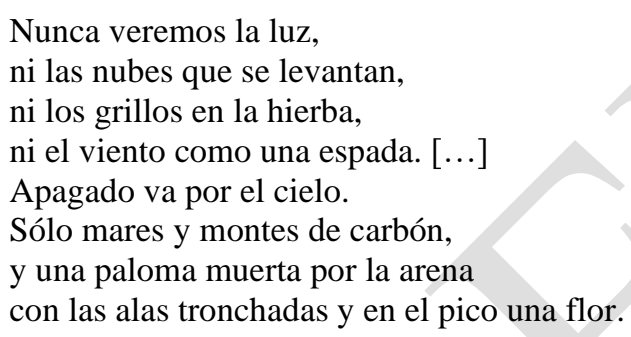

(García Lorca, $O C$, II, p. 345).

La misma idea defenderá la Vieja pagana en Yerma: "Dios, no. A mí no me ha gustado nunca Dios. ¿Cuándo os vais a dar cuenta de que no existe? Son los hombres los que te tienen que amparar" (García Lorca, OC, II, p. 490). Pero ya Así que pasen cinco años se asoma al "corazón de la desolación" (Steiner, 2011, p. 15), donde el sentimiento trágico se instala sin hacer caso a la promesa cristiana de la vida eterna. Respecto a la muerte, en Lorca, no hay compensación posible. Y, como recuerda Steiner (2011, p. 23), "conviene tener bien presente esta distinción. La tragedia es irreparable". La muerte joven es un tópico lorquiano por excelencia que en un sinnúmero de ocasiones se patentiza en imágenes de defunción infantil. Pero, claro está, la problemática en liza cobra nuevos tintes en esta comedia irrepresentable, ya que aquí el Niño muerto contrasta con el vivísimo Viejo, configurando un escenario contranatural que afirma la antinomia barroca (el juego entre claro y oscuro) mediante el paroxismo trágico.

Así pues, la tragedia del tiempo se patentiza en una deconstrucción del yo que igual coincide con una especie de invectiva fractal de la poética barroca. Según Ucelay (2006, pp. 78-79):

Lorca está haciendo lo que hiciera ya Góngora, que [...] dobla y triplica la imagen para llevarnos a planos diferentes necesarios para redondear la acción y comunicarla con todos sus aspectos. Desdobla, pues, [...] el pensamiento de su personaje central en proyecciones humanizadas de futuro, presente y pasado, muy al estilo [...] que hubiera hecho Calderón en un auto sacramental. 
Marie Laffranque (1987, p. 294) añade matices al identificar en la obra rasgos poéticos de los misterios. Pero la reincidencia de una estética religiosa en Así que pasen cinco años, más que en otros títulos del teatro de Lorca, no es ni casual ni arbitraria. Cumple recordar que, aunque fechado en 1931, el texto sigue ocupando la rutina de trabajo del poeta hasta sus últimos días, ya que justo en el verano de 1936, a las vísperas del estallido de la Guerra Civil y subsecuente asesinato de Lorca, Pura Ucelay preparaba el estreno de la obra bajo la vigilancia del autor, que aprovechaba la oportunidad para perfeccionar y actualizar el manuscrito. Aquellos años entre la primera y la última redacción de la pieza coincidieron por lo tanto con el proyecto de La Barraca, en el que Lorca puso en escena el auto La vida es sueño de Calderón, obra que parece estar detrás de los rasgos barrocos, pero también trágicos, de Así que pasen cinco años. El montaje de La Barraca estrenó en 1932 y se mantuvo en repertorio hasta el ocaso del grupo durante la Guerra Civil.

Y el auto calderoniano tiene mucho de la materia épica y trágica que a Lorca le ha interesado profundizar en el teatro imposible. En cierto modo, el auto da un acabado dramático a cuestiones ya presentidas en poemas fundacionales muy caros al poeta andaluz, como la Teogonía de Hesíodo (cf. García Lorca, $O C$, III, p. 70), tema sobre el que se ha volcado Agoglossakis (2012). Opera, en clave barroca, el conflicto primordial en el que la humanidad oscila entre el impulso de vitalidad (o, en términos cristianos, el libre albedrío) y la predestinación divina (o más bien el juicio final). Pero hablamos de un contexto histórico-artístico, el de las vanguardias españolas, donde la contaminación entre las distintas disciplinas artísticas está en el orden del día, de ahí que los escorzos oblicuos, la infinidad de curvas del arte barroco - es decir, las cristalizaciones visuales de la dialéctica sacramental - también interesen a artistas visuales y, muy en concreto, a escenógrafos (cf. Plaza Chillón, 2001, pp. 221-237).

Las pocas imágenes conservadas del montaje de La vida es sueño por los barracos atestiguan la apropiación, en clave surrealista, de códigos barrocos muy cercanos al imaginario onírico conseguido en la dramaturgia imposible de Lorca. Al fin y al cabo, La Barraca cumple el anhelo del autor respecto al desarrollo de una teatralidad renovadora y experimental, reforzada además por el carácter ambulante del grupo, destinado a otros públicos, preferentemente ajeno a los escenarios burgueses. "Lorca estaba obsesionado por la cuestión del público, sólo que tal aserto sólo es válido si tenemos en cuenta que para él se trataba ante todo de crear su propio público, que ya era otra manera de ver lo público $-\mathrm{y}$ por consiguiente lo privado_-" (Rodríguez, 1994, p. 55). La dimensión alegórica y, a la par, renovadora de Así que pasen hay que considerarla dentro de dicha perspectiva.

Desde el siglo XVIII vigoraba la prohibición de que los autos sacramentales se representasen fuera del contexto litúrgico, entendido en cuanto origen y razón de ser de dicha literatura (cf. Ucelay, 2006, p. 55). Insertada en las Misiones Pedagógicas y en el esfuerzo de laicización del sistema educativo español llevado a cabo por la Segunda República, La Barraca rompe con el paradigma dogmático con el que se solía leer la literatura aurea y pone de manifiesto la dimensión mítica de $L a$ vida es sueño. Se trata, según los barracos, de una obra antropológica, un poema épico sobre la creación 
del mundo y el triunfo de la humanidad. De ahí que el director Federico García Lorca, dirigiéndose a la audiencia, así se refiriese al auto de Calderón:

Es el poema de la creación del mundo y del hombre, pero tan elevada y profunda que en realidad salta por encima de las creencias [...]. La lucha de los cuatro elementos de la naturaleza por dominar el mundo, el terror del hombre $[\ldots]$ todavía tembloroso de arcilla y luz [...] y la escena de la Sombra con el pálido Príncipe de las Tinieblas son momentos dramáticos de difícil superación en ningún teatro. (García Lorca, $O C$, III, p. 221)

Al parecer, prevalecen las mismas claves de lectura que al conjunto de la Generación del 27 le ha interesado recoger de la tradición, o sea, el legado barroco percibido desde el punto de vista del proceder artístico: lo barroco, más que el barroco, por así decirlo. No sorprende, en este sentido, que estudios como el de Plaza Chillón, que analiza las imágenes conservadas del montaje de La Barraca, lleguen a conclusiones análogas a las que llegamos al asomarnos a Así que pasen cinco años. De ahí que el investigador califique La vida es sueño como una puesta en escena "casi hipnótica, de ensoñación, acercándose al mundo de lo onírico" (Plaza Chillón, 2001, p. 222).

La deconstrucción del sujeto mediante su multiplicación en distintas máscaras y juegos de espejismo está en el eje de las claves vanguardistas que Lorca pone en marcha en Así que pasen. La atmósfera sacramental, la que nos hace recordar los autos y misterios, viene también de ahí, de la dialéctica barroca y de sus contrastes radicales. Tal cual el Viejo se presenta en la obra de Lorca como un despliegue del Joven (un alter-ego, una voz de la conciencia), en el auto de Calderón el juego de simetrías también se anuncia, sobre todo en las figuras de la Sombra y del Príncipe de las Tinieblas. Se trata en efecto de los personajes mencionados por Lorca en su discurso al público. La Sombra, interpretada justamente por Lorca en el montaje de La Barraca, es el portavoz alegórico del presente absoluto de Calderón. Como si estuviera ya en el seno mismo de la comedia irrepresentable del siglo $\mathrm{XX}$, el personaje barroco enunciaba el asombro ante la muerte ya tan presente en poesía mística y que, luego, vertebrará las figuras de Lorca:

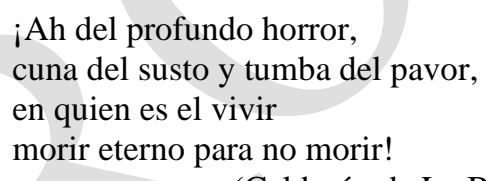

(Calderón de La Barca, La vida es sueño, vv. 521-524).

Y, llegado a este punto, hay que hacer cierto hincapié en un hecho insoslayable: Lorca es un hombre de teatro, un artista de las tablas. Es más o menos recurrente la afirmación de que la dramaturgia en el Grupo del 27 juega un papel secundario, en el sentido de que los escenarios se constituyen no tanto como una vocación natural de la generación, sino como espacios sociales de consagración literaria y, consiguientemente, canonización de un autor. Si bien no se puede negar el rol desempeñado por la colaboración con la compañía de Margarita Xirgu en la consolidación de Lorca en el campo literario, hay que convenir en que, en el caso del poeta andaluz, el teatro cumple con un anhelo particular de intervención artística. Atestigua esta preocupación la persistencia del autor en los temas esencialmente teatrales: empieza los años veinte involucrado con la recuperación de la tradición 
titiritera de Andalucía, enseguida toma contacto con prácticas punteras del teatro neoyorquino al tiempo que se entera de las teorías y prácticas teatrales en boga en Europa para, a lo largo de los años treinta, invertir en proyectos escénicos renovadores, como lo son La Barraca o las comedias irrepresentables insertadas en prácticas colectivas y experimentales como el Club Teatral Anfistora.

Dentro de dicho contexto, Así que pasen cinco años se confirma como una especie de tratado teatral lorquiano. Saillard y Ramond (1998, p. 7) afirman que la obra de 1931 es una especie de "l'avant-Público". La idea de teatro del porvenir que atraviesa las comedias irrepresentables es un concepto estético pero también sociohistórico: Lorca tiene claro que sus escritos de vanguardia se destinan a otro público, un público quizás del mañana. Así pues, El público nace bajo el estigma de la autocensura: es una comedia imposible, también porque resulta imposible hablar abiertamente sobre la homosexualidad, tema explícito en la obra, en los escenarios de aquel entonces. De ahí que poco se añada al manuscrito acabado en La Habana en 1930.

En cambio, Así que pasen cinco años merecerá la atención del poeta a lo largo de muchos años. Al tratarse de una obra en la que los temas morales se disfrazan, en cierto modo, en las entrelíneas, mediante alegorías y juegos metafóricos, la posibilidad de estrenarla es ilusionante: Así que pasen convierte lo imposible en posible y, además, cumple con los requisitos de aportar libertad poética al teatro, rompiendo con el canon burgués y proponiendo una nueva teatralidad, ajena a los preceptos aristotélicos o más bien al modelo dramático marquiniano.

Aunque sabemos que la fugacidad del tiempo, lo efímero de la vida y el asombro ante la muerte atraviesan toda la obra de Lorca, cumple reconocer que Así que pasen cinco años quizás sea, en su teatro, el más bien conseguido ejemplo de tal proyecto dramático. Doña Rosita seguramente padece del mismo fado trágico que el Joven, pero si en la obra de 1935 Lorca experimentará una atmósfera chejoviana marcada por cierto naturalismo burgués, en Así que pasen la desolación del protagonista ante una potencia con la que no puede — el tiempo que funciona como un daimon trágico—, se plasma en una estética radical, que concuerda enteramente con su estado síquico.

El torbellino emocional de su flagelo ante el desamor, sumado a su temor a la muerte, encuentra en la deconstrucción de las formas dramáticas (la discontinuidad narrativa, la fragmentación de la conciencia, etc.) una perfecta estilización, un paso importante para reubicar el sentido trágico. Al fin y al cabo, el misterio de la existencia que asombraba a Esquilo, pero también a Calderón, encuentra aquí una proyección hacia el porvenir. Dijo Steiner $(2011,15)$ : "No hacen falta tempestades cósmicas ni bosques peregrinos para llegar al corazón de la desolación. Basta la ausencia de una silla".

\section{Referencias bibliográficas}

AgOGlossakis, Stavros (2012). 'Hesíodo y la poesía juvenil de Federico García Lorca', en Laura Silvestri et. al. (eds.), Actas del XVII Congreso de la Asociación Internacional de Hispanistas: Rumbos del hispanismo en el umbral del Cincuentenario de la AIH, vol. V, 152-159. Alicante: 
72 Tropelías. Revista de Teoría de la Literatura y Literatura Comparada, 33 (2020)

Claudio Castro Filho

Centro Virtual Cervantes. Disponible en: https://cvc.cervantes.es/literatura/aih/pdf/17/aih_17 5_022.pdf.

Alonso VAlero, Encarna (2008). La tragedia del nacimiento: el teatro de Federico García Lorca. Granada: Atrio.

ALONSO VALERO, Encarna (2005). No preguntarme nada: variaciones sobre tema lorquiano. Granada: Atrio.

BACHELARD, Gaston (1997). La poética de la ensoñación, trad. Ida Vitale. México: Fondo de Cultura Económica.

CAlderón de la BARCA, Pedro (1981). La vida es sueño. Drama y auto sacramental, ed. José María Valverde. Barcelona: Planeta.

CAMPILlo, Antonio (1991). 'Aión, chrónos y kairós: la concepción del tiempo en la Grecia antigua', La(s) otra(s) historia(s), 3, 33-70.

CANDEIAS, Maria Lúcia (2012). A fragmentação da personagem. São Paulo: Perspectiva.

DeVEReuX, George (1975). Dreams in Greek Tragedy: An Ethno-Psycho-Analytical Study. Oakland: University of California Press, 1975.

Degani, Enzo (2001). Aion. Da Omero a Aristotele. Bologna: Pàtron.

FouCAUlt, Michel (2005). Las palabras y las cosas: una arqueología de las ciencias humanas, trad. Elsa Cecilia Frost. Buenos Aires, México: Siglo Veintiuno.

GARCía LORCA, Federico (1997). Obras completas, 4 vols., ed. Miguel García-Posada. Barcelona: Galaxia Gutenberg.

KeIZER, Helena Maria (1999). Life Time Entirety. A Study of AION in Greek Literatura and Philosophy, the Septuagint and Philo. Amsterdam: Universiteit Amsterdam [PhD Thesis].

LAFFRANQUE, Marie (ed.) (1987). Federico García Lorca. Teatro inconcluso: fragmentos y proyectos inacabados. Granada: Universidad de Granada.

MARQUES, Susana (2006). Sonhos e visões na tragédia grega. Coimbra: Universidade de Coimbra.

OniAns, R. B. (1988). The Origins of European Thought: About the Body, the Mind, the Soul, the World, Time and Fate. Cambridge: Cambridge University Press, 2nd ed.

Plaza ChILlón, José Luis (2001). Clasicismo y vanguardia en La Barraca de Federico García Lorca. Granada: Comares.

RODRÍGUEZ, Juan Carlos (1994). Lorca y el sentido: un inconsciente para una historia. Madrid: Akal. SAILlARD, Simone, y RAMOND, Michele (1998). Le théâtre impossible de García Lorca: Así que pasen cinco años, El Público. Paris: Messene.

SÉNECA, Lucio Anneo (2008). Medea, trad. Miguel de Unamuno. Mérida: Consorcio Patronato Festival de Teatro Clásico de Mérida.

STEINER, George (2011). La muerte de la tragedia, trad. Enrique Luis Revol. Madrid: Siruela.

UCELAY, Margarita (ed.) (2006). Federico García Lorca. Así que pasen cinco años. Madrid: Cátedra. 